This item was submitted to Loughborough's Research Repository by the author.

Items in Figshare are protected by copyright, with all rights reserved, unless otherwise indicated.

\title{
Whole body vibration in helicopters: risk assessment in relation to low back pain
}

PLEASE CITE THE PUBLISHED VERSION

http://dx.doi.org/10.3357/ASEM.2982.2011

\section{PUBLISHER}

(c) Aerospace Medical Association

VERSION

AM (Accepted Manuscript)

LICENCE

CC BY-NC-ND 4.0

\section{REPOSITORY RECORD}

Kasin, Jan Ivar, Neil J. Mansfield, and Anthony Wagstaff. 2019. "Whole Body Vibration in Helicopters: Risk Assessment in Relation to Low Back Pain”. figshare. https://hdl.handle.net/2134/8737. 
This item was submitted to Loughborough's Institutional Repository (https://dspace.lboro.ac.uk/) by the author and is made available under the following Creative Commons Licence conditions.

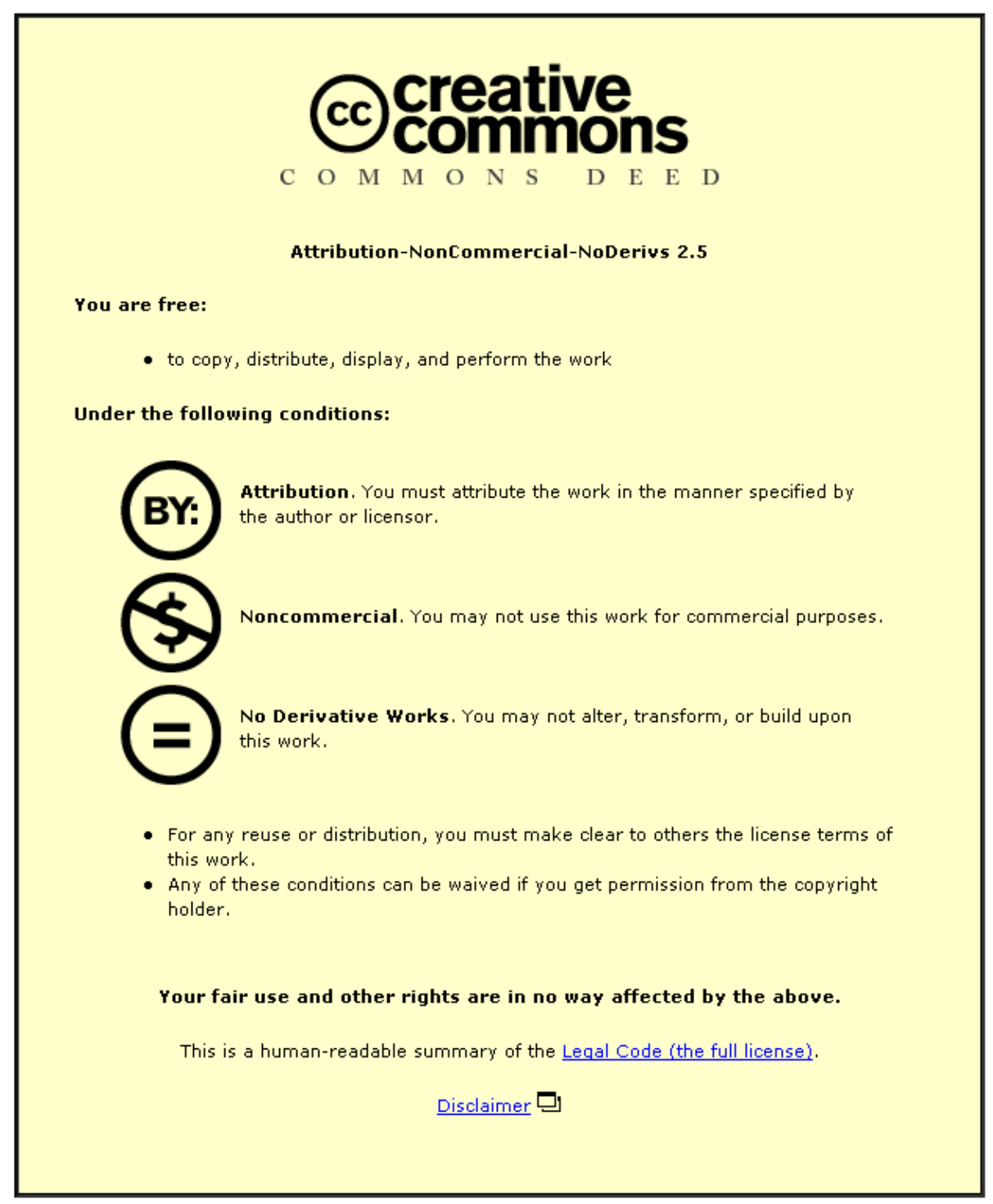

For the full text of this licence, please go to: http://creativecommons.org/licenses/by-nc-nd/2.5/ 
Whole body vibration in helicopters; risk assessment according to the European vibration directive.

Jan Ivar Kåsin ${ }^{1}$ MSc

Neil Mansfield ${ }^{2} \mathrm{PhD}$, BEng

Anthony Wagstaff ${ }^{1}$ MD, DAvMed, PhD, MBA

1 Institute of Aviation Medicine, Oslo, Norway

${ }^{2}$ Environmental Ergonomics Research Centre, Loughborough University, Loughborough, LE11 3TU, UK.

Suggested short title: Helicopter WBV risk assessment

Word count abstract: 249

Word count narrative text:

Number of references: 34

Number of tables: 3

Number of figures: 1

Keywords: Helicopter Pilot, ISO 2631-1, Low Back Pain 


\section{ABSTRACT}

Introduction: Helicopter pilots are exposed to whole body vibration (WBV) in their working environment. WBV has been associated with low back pain (LBP) and helicopter pilots have a high prevalence for LBP compared with other professions. The aim of this study was to develop a test protocol for measuring helicopters with ISO 2631-1 and to perform a wholebody vibration risk assessment based on the European Vibration Directive in a number of commonly used military and civilian helicopters. Both absolute values and individual difference in current helicopter types are of interest, in order to evaluate the possible role of vibration in LBP in helicopter pilots. Methods: 6 helicopters were tested in operationally relevant manoeuvres. In order to standardise measurements each continuous flight was split into 15 separate manoeuvres. A model of a working day exposure pattern was used to calculate A(8) vibration magnitudes for each helicopter. Results: The vibration $\mathrm{A}(8)$ exposure estimates ranged from $0.32-0.51 \mathrm{~m} / \mathrm{s}^{2}$ during an 8 hour working day $\mathrm{A}(8)$. This compares with EU and ISO lower bounds risk criteria of 0.5 and $0.43 \mathrm{~m} / \mathrm{s}^{2} \mathrm{~A}(8)$ respectively. Discussion: Despite the vibration levels being relatively low, helicopter pilots report a high incidence of LBP. It is possible that helicopter pilot postures increase the risk of LBP when combined with WBV. The test protocol used in this study could be generally applied for other rotary winged aircraft testing to allow for comparison of WBV results. Data from different flight phases could be used to model different exposure profiles. 


\subsection{INTRODUCTION}

Helicopters are complex machines with many parts in rotational movement used in all kind of weather conditions with changing temperature, air pressure and wind. The main rotor, tail rotor gearbox and turbine engine interacts with the different environmental factors, resulting in a degree of vibration inside the aircraft. This vibration is transmitted to the aircrew at all contact surfaces, including floor, control devices, and seating. It is known that vibration has various effects on exposed workers, low back pain (LBP) being the most common health complaint $(6,19)$. LBP is associated with a number of occupations and activities. LBP has numerous different aetiologies and pathophysiology and its presentation is subjective and individual (26). Low back pain is associated with people who are operating different types of vehicles, taxis (9), trucks (22) military armoured vehicles (23), fork lift trucks (5) as well in helicopter pilots $(4,14,30)$. The Norwegian Institute of Aviation Medicine has previously investigated the prevalence of LBP problems in helicopter and fixed wing environments finding that $50 \%$ of the helicopter pilots reported such pain in a 2 year period retrospectively. In the same period fixed wing pilots reported a prevalence of only $18 \%$ (14). In a recent review study helicopter Pilots were found to be the occupational group that had the strongest association with LBP (17).

Whole body vibration (WBV) has been associated with LBP, sciatic pain, and degenerative change in the spinal system including lumbar intervertebral disc disorders (7). The European Directive on human exposure to mechanical vibration provides qualitative and quantitative guidance to protect workers against the risks arising from exposure to vibration at work. In the Directive, WBV is defined as "the mechanical vibration that, when transmitted to the whole body, entails risks to the health and safety of workers, in particular lower-back 
morbidity and trauma of the spine', (1). The Directive states that risks from vibration should be minimised and that an employee should not be exposed for more than $1.15 \mathrm{~m} / \mathrm{s}^{2}(\mathrm{~A}(8)$ exposure limit value) during an eight hour working day measured according to ISO 2631-1 (27). The exposure action value is $0.5 \mathrm{~m} / \mathrm{s}^{2}$. These are 8-hour dose measures; therefore a vibration magnitude higher than these thresholds could be allowed if exposure times are less than 8 hours. If the exposure action is exceeded then protective measures should be taken to isolate the worker from vibration, health surveillance implemented and worker training on risks from vibration. The thresholds and required actions are designed to protect workers from negative health effects on the lumbar spine.

In an Informative Annex, ISO 2631-1 defines a 'health guidance caution zone' with boundaries of 0.43 and $0.87 \mathrm{~m} / \mathrm{s}^{2} \mathrm{~A}(8)$. The standard states that for exposures that exceed the zone health risks are 'likely' and that for exposures below the zone health effects have 'not been clearly documented and/or objectively observed'. These thresholds are not legally binding or enforceable. Therefore, in this paper the EU criteria are used as the primary exposure thresholds.

It is usually assumed that if vibration exposures are below the EU action value, WBV is unlikely to be a significant risk factor for LBP. Since helicopter pilots have a high incidence of LBP and since helicopters have a substantial degree of vibration one could hypothesize that helicopter pilots are exposed to vibration exceeding the action value of $0.5 \mathrm{~m} / \mathrm{s}^{2}$, possibly exceeding the limit value of $1.15 \mathrm{~m} / \mathrm{s}^{2} \mathrm{~A}(8)$. In addition to vibration, posture is known as a factor to consider in relation to LBP (8). Although the EU Directive states that the design and layout of workspaces should be considered, there is no guidance or criteria for posture assessment either in the Directive or ISO 2631-1. Furthermore no standard test protocol exists for measuring helicopters using ISO 2631-1 and there are no known publicly available data 
sets of vibration exposure thus making it difficult to estimate exposures as part of a vibration risk assessment.

The aim of this study was to develop a test protocol for measuring helicopters with 2631-1 and to perform a whole-body vibration risk assessment based on the European Directive 2002/44/EC on mechanical vibration in a number of commonly used military and civilian helicopter types. Both absolute values and individual difference in current helicopter types are of interest, in order to evaluate the possible role of vibration in LBP in helicopter pilots. 


\subsection{METHODS}

The Norwegian Institute of Aviation Medicine contributes to the health and safety for flying personnel for The Royal Norwegian Air Force (RNoAF). The Institute provides research, testing and medical approval of aviation staff, as well as advice upon projects within flight operations working environment.

\section{Subjects}

Vibration was assessed at 3 active air force squadrons in the period 2005-2010. These squadrons operate three different helicopter types. The pilot flying the military helicopters weighed $93 \mathrm{~kg}$.

-Bell 412SP, Bell Helicopter Textron, Forth Worth, Texas, USA

-Westland Sea Lynx MK 86, Westland Helicopters, Yeovil, England

-Westland Sea King MK 43B, Westland helicopters, Yeovil, England

The Bell 412SP is mainly used for troop transportation and medical evacuation. The helicopter has four rotor blades and equipped with two Pratt \& Whitney PT6T-turboshaft engines. Westland Sea Lynx is a 4 bladed helicopter with two Rolls-Royce Gem-turboshaft engines. The helicopter was originally intended as a utility craft for both civil and naval usage. The RNoAF has stationed the helicopter on board the coast guard vessels. The Sea King is a 5 bladed search and recue helicopter with two Rolls-Royce Gnome single spool turboshaft engines.

Three different civilian helicopters from Bristow Norway AS and Oslo Police Department were also measured. The pilots flying the civilian helicopters weighed $79+/-5 \mathrm{~kg}$. 
-S-92A, Sikorsky Aircraft Corp, Stratford, Connecticut, USA

-EC135 T2, Eurocopter, Marignane Cedex, France

-Super Puma L2, Eurocopter, Marignane Cedex, France

Two different configurations of the S-92A were measured. The S-92A is equipped with 3 or 6 anti-vibration generators (AVGs). AVGs actively reduce the vibration in the blade pass frequency area at $17.2 \mathrm{~Hz}$ by generating vibration with a 180 degree phase shift. EC135 is a police helicopter with camera-pod, search light and $210 \mathrm{~kg}$ of extra electronic equipment mounted under the airframe.

Each individual helicopter was subject to a pre-flight documentation check for any history of abnormal vibration problems as reported by recent technical evaluations, in order to ascertain the representativeness of that particular helicopter individual in relation to the vibration levels of that helicopter type.

No objective measures of LBP or subject postures were taken due to the small sample size of the available pilots.

\section{Equipment}

A standard measurement pad which has accelerometers fitted in 3 axes (Endevco, type 2560, Brüel \& Kjær, Denmark) was used for the sampling of whole body vibration. This was connected to a data-acquisition front end (Type 3560C, Brüel \& Kjær, Denmark). Data was stored on a portable PC with acquisition and analysis software (Pulse Labshop 10.0, Brüel \& Kjær, Denmark). 


\section{Profiles and time spent in each profile}

No standard test protocol exists for measurement of vibration in helicopters. In order to standardise measurements each continuous flight was split into separate manoeuvres that were representative for the typical operational use of the specific helicopter type. Measurements were therefore undertaken in 15 different profiles drawn up with the assistance of a test pilot from the RNoAF. Since the helicopters differed and had differing operational characteristics, they were flown at different speeds which were representative in relation to each profile (Table I). Flights were performed by the same test pilot for all three military helicopters and with different pilots in the civilian helicopters.

In order to compare the military helicopters, assistance from a test pilot from the RNoAF was used to draw up a theoretical distribution between different profiles and converted this into a theoretical working day; 'Military Range' (Table II). The times are not necessarily representative in all aspects of the detailed operating pattern of every helicopter, but they enable comparisons to be made between all the helicopters if they had performed the same flight profile for 8 hours. Pilots in the RNoAF fly 150-350 hours annually, while pilots in commercial companies operating with transportation to oil rigs in the North Sea fly $700-800$ hours per year. However, according to the Directive, risk assessments must be completed on a 'per day' basis, rather than averaged over several days. Commercial pilots' work is more standardised with up to 5-7 hours flying time per day. In order to produce a working day for this group that was as realistic as possible, an experienced pilot from the industry drew up a representative 8 hour working day; 'Civilian Range' (Table II). The helicopters that operate according to this profile are Sikorsky S-92 and the Eurocopter Super Puma L2. The EC 135 is widely used amongst police and ambulance services and for executive transport and we place it in the civilian range even its operational use may vary from the helicopters used offshore. 
\#TABLE I\#

\section{\#TABLE II\#}

\section{Assessment methods}

Whole-body vibration in helicopters was assessed in relation to the European Directive 2002/44/EC and was performed in accordance with ISO 2631-1:1997 in right pilot position. It was assumed that ISO 2631-1 frequency weightings were appropriate for assessing helicopter vibration. Each vibration profile was measured for 60 seconds and the measurement was started manually by test operator when the pilot had stabilized the helicopter according to the profile. The measurement range was $0.5-80 \mathrm{~Hz}$. Vibration was recorded in the $\mathrm{x}, \mathrm{y}$ and $\mathrm{z}$ directions with a sampling rate of $62.5 \mathrm{kHz}$. The vibration axes were weighted in accordance with the standard, the $\mathrm{x}$ and $\mathrm{y}$ axes being given a $\mathrm{W}_{\mathrm{d}}$ weighting, while the $\mathrm{z}$ axis was given a $\mathrm{W}_{\mathrm{k}}$ weighting. Frequency weightings were applied in the frequency domain. The $\mathrm{x}$ and $\mathrm{y}$ direction data were multiplied by 1.4 in accordance with requirements for health assessments in Annex B of ISO 2631-1. The value to be compared with action and limit values in the directive is the daily exposure values $\mathrm{A}(8)$. When a working day is composed of two or more periods of exposure to different magnitudes and durations, the energy-equivalent vibration magnitude corresponding to the total duration of exposure, was calculated in $\mathrm{x}, \mathrm{y}$ and $\mathrm{z}$-axis according to the formula in ISO 2631-1:

$$
A_{l}(8)=k_{l} \sqrt{\frac{1}{T_{0}} \sum_{i} a_{w l i}^{2} T_{i}}
$$

where 
$A_{l}(8)$ is the daily vibration exposure in $\mathrm{m} / \mathrm{s}^{2}$ for each direction $l$

$a_{w l i}$ is the frequency-weighted r.m.s. value of the acceleration, determined over the time period $T_{i}$

$l=\mathrm{x}, \mathrm{y}, \mathrm{z}$

$k_{x}=k_{y}=1,4$ for the $\mathrm{x}$ - and $\mathrm{y}$-directions; $k_{z}=1$ for the z-direction

$T_{\mathrm{o}} \quad$ is the reference duration of $8 \mathrm{~h}(28800 \mathrm{~s})$

The overall highest axes are used further in the assessment. 


\subsection{RESULTS}

The z-axes had the overall highest vibration levels in all the helicopters. Results show variation in vibration levels between the helicopter types and the different profiles. Max speed and turn left $45^{\circ}$ were the two profiles with the average highest vibration levels. There were no clear trends regarding ranking of vibration levels for the other flight profiles. Sea King and Super Puma were the helicopters with the overall lowest vibration levels. EC 135 and Bell 412 have marginally higher vibration levels. The Sea Lynx and S-92s were the helicopters with the highest vibration levels where S-92 3 AVG were just above the EU action level. By processing the RMS values with time spent in each profile we calculated the theoretical working day vibration exposure for a military helicopter pilot and for a civilian helicopter pilot flying offshore. The $\mathrm{A}(8)$ value was calculated according to the formula in ISO 2631-1:1997 (with 2010 amendment).The measurement results for all helicopters and profiles are presented in Table III, showing the vibration levels in weighted RMS values of the different profiles. Only 5 out of 105 profiles had dominant vibration in the $\mathrm{x}$ - or $\mathrm{y}$-axis, and $\mathrm{z}$-axis was therefore the overall highest axes to be compared with the EU vibration levels (Figure I).

\section{\#TABLE III\#}

\section{\#FIGURE I\#}




\subsection{DISCUSSION}

Since measurements are both time consuming and expensive, repeated measurements on all individuals were not feasible. Repeated measurements with 3-month intervals were made on one helicopter, the S-92A 6 AVG. The difference in the A(8) value between the measurements was $0.03 \mathrm{~m} / \mathrm{s}^{2}$. Similar results were obtained by a manufacturer during series of measurements using the 15 profiles 3 times. The results were comparable with our measurements. In addition, the manufacturer concurred that these data are generally representative of the aircraft type (Frederickson KC, Senior Technical engineer, Sikorsky, Personal communication; 2010). The test data showed co-efficients of variation comparable with our measurements, confirming that vibration emissions are repeatable for these aircraft. There was no significant relationship between aircraft speed and vibration magnitudes.

By computing the 8-hour day on every helicopter type one would usually overestimate the vibration levels for a typical working day, as most missions do not last 8-hours. On the other hand since there is no standardised helicopter mission, the vibration level will vary between every mission dependent on the duration. As the EU Directive does not allow for averaging over more than one day, the exposure thresholds need to be assessed for the worst case. In order to compare the vibration levels, both the profiles and working day were standardised. 8 hours were chosen because there are helicopter pilots that could occasionally fly that many hours per day. This is also a standard workday for other workplaces, enabling comparison. Only S92 3AVG found to exceed the EU action level of $0.5 \mathrm{~m} / \mathrm{s}^{2}$ during an 8 hour working day A(8), and was the only helicopter that exceeded the lower boundary of the ISO 2631-1 health guidance caution zone. The vibration $\mathrm{A}(8)$ exposures ranged from $0.32-0.51 \mathrm{~m} / \mathrm{s}^{2}$ in 
Z-axis. These levels are within the safe zone except for one helicopter. The results are sampled in right pilot position but it is reason to believe that the vibration levels can vary slightly from our results in left pilot position. $\mathrm{A}(8)$ daily occupational vibration exposure will usually be lower in practice for both military and civilian pilots since they generally fly less than 8 hours per day. Alternative exposure models could be used to estimate $A(8)$ vibration for other working patterns and using the data in Table III. These data show that although it could be possible for a pilot to exceed thresholds for health risk, it will be an irregular occurrence, and there would be no instances of exceeding the EU exposure limit value or the upper boundary of the ISO health guidance caution zone in normal operation.

This study indicates that helicopter aircrew should not be in the risk zone for vibrationinduced LBP. However, there is no evidence in the literature that WBV below the action level does not affect the lumbar area in humans and there is no universally agreed threshold for risk / no risk. There are few studies that suggest any dose-response relationship between WBV and back problems and none of these studies have determined any clear level where WBV is safe regarding LBP risk $(6,24)$. This is accepted in the Directive, as it states that any risk from vibration should be minimised, irrespective of the magnitude. One longitudinal study has described the problem of precisely quantifying vibration load in connection with evaluation of low-back disorders. It is also difficult to isolate and evaluate the effect of a single strain like vibration when several occupational strain sources are present (24).

The posture of all pilots was slightly forward with a decreased or absent lordosis of the lower back together with a slight scoliosis to the left side due to the collective. This is typical and is present in all helicopters while flying actively. As civilian helicopters flying in the North Sea generally have more advanced autopilot systems, it could be hypothesized that this gives 
pilots a greater opportunity for rest and postural variation. Future research should identify and assess these postural changes using more objective methods.

A review paper on the association between sitting and occupational LBP points out that helicopter pilots are the occupational group that has the strongest association with LBP, suggesting the pilots' awkward sitting posture in helicopter as a major factor (17). These results coincide with a number of other studies, where posture is mentioned as the more important etiological factor $(8,25,30)$. The high incidence of LBP is suggested to be a pilot problem, since pilots needs to adopt a twisted, forward-bent position, more than a general crew problem. In one study helicopter pilots reported LBP six times more often than other crew members (14). A cross-over study with pilots flying alternately in the front and rear positions was used to assess the effect of crew position on the prevalence of LBP during flight. In the pilot's seat there was an increased prevalence of pain, the onset of pain was quicker and the intensity was greater (11). This has been investigated by others where those sitting in a fixed position had higher incidence of LBP compared to those who were allowed to move more freely (31). That there is a link between spinal posture and LBP is therefore well established, but the mechanics and biological processes in various postures that lead to LBP are not fully understood (20).

Even if posture seems to be an important factor alone, there are indications that the influence of vibration and posture together will increase the prevalence for LBP (21). By comparing helicopter pilots with fixed-wing pilots, LBP occurrence during a two year period for fixedwing pilots was $18,2 \%$ and for helicopter pilots $50,5 \%$ (14). Fixed wing pilots have a relatively neutral posture and are not forced to sit leaning in a forward and twisted position. It is also known that the normal vibration levels in fixed wing aircraft are less than that in helicopters (33). Vibration levels measured in C-130J (Lockheed Martin, Fort Worth, Texas, 
USA) are only $\approx 0.1 \mathrm{~m} / \mathrm{s}^{2}$ during cruise 240 knots JAS in captain and co-pilot position and much lower compared to helicopters as measured here.

Any tool for assessing combined vibration and postural risk should work for no vibration conditions. Describing and appropriately assessing an awkward posture is a challenge. Common posture assessment tools lack sensitivity and are not designed for seated postures, or for scenarios where the subject is required to use both arms and legs dynamically, such as that required for a helicopter pilot (28).

The spine itself is an unstable structure and adequate stability has to be provided by the musculature (29). It is known that posture affects the muscular activity in the lower back region and studies show that a twisted position results in asymmetric trunk muscular activity with increased agonist activity with increased angle of twist. All muscular activity, depending on the duration and physical load will result in muscle fatigue $(2,12)$. During isometric muscle work in an asymmetric twisted posture it is assumed that contraction causes increased tissue pressure resulting in compromised perfusion and tissue hypoxia. Tissue hypoxia accelerates the muscle fatigue process and prolonged contraction inducing hypoxia could therefore be an explanation for low back pain (15). The individual variation in muscle activation during asymmetric posture is large and this variation could give a clue to why some subjects develop LBP and other do not (32). Lumbar back muscle activity of helicopter pilots tested in real helicopter environments showed EMG activity corresponding to less than $5 \%$ of maximal voluntary contraction on both sides of erector spinea (ES) according to a study that did not reveal any posture effect. The EMG level was comparable to a seated person outside a helicopter environment (10). Still various studies show different results. One helicopter mock up study revealed increased right sided EMG activity on ES muscle during a simulated flight. The findings were related to asymmetric posture (18). That there is a link between spinal 
posture and LBP is therefore well established, but the mechanics and biological processes in various postures that lead to LBP are not fully understood (20).

There are many factors to consider when assessing LBP and we have no reliable methods to integrate all the factors in order to determine their relative importance. Muscle fatigue is a possible cause. Degeneration of the intervertebral discs is also presented as a possible cause of LBP. No studies clearly show the extent to which it is vibration, posture or other factors that are causal factors in degeneration. Specifically, there is very little, if any, evidence that helicopter pilots suffer increased levels of degeneration of the vertebral spine (1).

Degenerative changes seemed to be associated with older age rather than aircraft type (16). Disc degeneration in general has a complex multifactorial aetiology and it is difficult to determine whether the condition is genetic, due simply to ageing, or traumatic (13). A retrospective twin study suggest that disc degeneration may be explained primarily by genetic influences and only to a lesser extent influenced by working environment factors often suspected of accelerating disc degeneration (3). Based on the above, there is little reason to believe that the levels of vibration we have measured would increase degenerative disease of the spine.

A range of the most common helicopter types in Norway; both military and civilian have been measured. These are also commonly used types in most parts of the world. It is a fair assumption that an average of the values measured at this range of different helicopter types is representative for single rotor twin turbine helicopters in general, taken into account the relative small variation measured. Very few helicopter pilots would spend 8 hours per day flying, making it unlikely that the majority of these pilots would experience a vibration level above the action level set by the European Directive 2002/44/EC or the ISO 2631-1 health guidance caution zone. This is true for both military and civilian helicopter pilots. However, 
total daily vibration dose could be increased if the pilots other duties or leisure activities involve exposure to whole-body vibration.

Despite the vibration levels being relatively low, helicopter pilots report a high incidence of LBP. It is therefore likely that the cause of the LBP is not solely due to WBV. There are indications that posture is an important factor to consider. Posture should therefore be considered as part of the risk assessment when applying the EU vibration directive and ISO 2631-1. Further studies are needed to understand the mechanisms for the interaction between posture and vibration in helicopter low back pain, thereby leading the way to better preventive strategies in the future. The test protocol used in this study could be generally applied for other rotary winged aircraft testing to allow for comparison of results between different helicopter types. 


\section{References}

1. The minimum health and safety requirements regarding the exposure of workers to the risks arising from physical agents (vibration). Official Journal of the European Communities. 2002 25. June 2002(2002/44/EC):7.

2. Albert WJ, Sleivert GG, Neary JP, Bhambhani YN. Monitoring individual erector spinae fatigue responses using electromyography and near infrared spectroscopy. Can J Appl Physiol. 2004;29(4):363-78.

3. Battie MC, Videman T, Gibbons LE, Fisher LD, Manninen H, et al. 1995 Volvo Award in clinical sciences. Determinants of lumbar disc degeneration. A study relating lifetime exposures and magnetic resonance imaging findings in identical twins. Spine. 1995;20(24):2601-12.

4. Borrillo DJ. Back pain in helicopter pilots. Aviat Space Environ Med. 1999 May;70(5):533-4.

5. Boshuizen HC, Bongers PM, Hulshof CT. Self-reported back pain in fork-lift truck and freight-container tractor drivers exposed to whole-body vibration. Spine. 1992 Jan;17(1):59-65.

6. Bovenzi M. Metrics of whole-body vibration and exposure-response relationship for low back pain in professional drivers: a prospective cohort study. Int Arch Occup Environ Health. 2009;82(7):893-917.

7. Bovenzi M, Hulshof CT. An updated review of epidemiologic studies on the relationship between exposure to whole-body vibration and low back pain (19861997). Int Arch Occup Environ Health. 1999;72(6):351-65.

8. Bridger RS, Groom MR, Jones H, Pethybridge RJ, Pullinger N. Task and postural factors are related to back pain in helicopter pilots. Aviat Space Environ Med. 2002;73(8):805-11.

9. Chen JC, Chang WR, Chang W, Christiani D. Occupational factors associated with low back pain in urban taxi drivers. Occup Med (Lond). 2005;55(7):535-40.

10. de Oliveira CG, Nadal J. Back muscle EMG of helicopter pilots in flight: effects of fatigue, vibration, and posture. Aviat Space Environ Med. 2004;75(4):317-22. 11. Froom P, Hanegbi R, Ribak J, Gross M. Low back pain in the AH-1 Cobra helicopter. Aviat Space Environ Med. 1987;58(4):315-8.

12. Gandevia SC. Spinal and supraspinal factors in human muscle fatigue. Physiol Rev. 2001 Oct;81(4):1725-89.

13. Hadjipavlou AG, Tzermiadianos MN, Bogduk N, Zindrick MR. The pathophysiology of disc degeneration: a critical review. J Bone Joint Surg Br. [Review]. 2008;90(10):1261-70.

14. Hansen OB, Wagstaff AS. Low back pain in Norwegian helicopter aircrew. Aviat Space Environ Med. 2001;72(3):161-4.

15. Kramer M, Dehner C, Hartwig E, Volker HU, Sterk J, et al. Intramuscular pressure, tissue oxygenation and EMG fatigue measured during isometric fatigueinducing contraction of the multifidus muscle. Eur Spine J. 2005;14(6):578-85.

16. Landau DA, Chapnick L, Yoffe N, Azaria B, Goldstein L, et al. Cervical and lumbar MRI findings in aviators as a function of aircraft type. Aviat Space Environ Med. 2006;77(11):1158-61.

17. Lis AM, Black KM, Korn H, Nordin M. Association between sitting and occupational LBP. Eur Spine J. 2007;16(2):283-98.

18. Lopez-Lopez JA, Vallejo P, Rios-Tejada F, Jimenez R, Sierra I, et al. Determination of lumbar muscular activity in helicopter pilots: a new approach. Aviat Space Environ Med. 2001;72(1):38-43. 
19. Magnusson ML, Pope MH, Wilder DG, Areskoug B. Are occupational drivers at an increased risk for developing musculoskeletal disorders? Spine. 1996;21(6):710-7. 20. Mitchell T, O'Sullivan PB, Burnett AF, Straker L, Smith A. Regional differences in lumbar spinal posture and the influence of low back pain. BMC Musculoskelet Disord. 2008;9:152.

21. Okunribido OO, Magnusson $\mathrm{M}$, Pope $\mathrm{MH}$. The role of whole body vibration, posture and manual materials handling as risk factors for low back pain in occupational drivers. Ergonomics. 2008 Mar;51(3):308-29.

22. Robb MJ, Mansfield NJ. Self-reported musculoskeletal problems amongst professional truck drivers. Ergonomics. 2007;50(6):814-27.

23. Rozali A, Rampal KG, Shamsul Bahri MT, Sherina MS, Shamsul Azhar S, et al. Low back pain and association with whole body vibration among military armoured vehicle drivers in Malaysia. Med J Malaysia. 2009;64(3):197-204.

24. Schwarze S, Notbohm G, Dupuis H, Hartung E. Dose-response relationships between whole-body vibration and lumbar disk disease--A field study on 388 drivers of different vehicles. Journal of Sound and Vibration. 1998;215(4):613.

25. Shanahan DF, Reading TE. Helicopter pilot back pain: a preliminary study. Aviat Space Environ Med. 1984;55(2):117-21.

26. Skovron ML. Epidemiology of low back pain. Baillieres Clin Rheum. 1992;6(3):559-73.

27. Standardization IOf. ISO 2631-1 Mechanical Vibration and shock - Evaluation of human exposure to whole-body vibration. 1997.

28. Standardization IOf. ISO/TR 10687 Mechanical vibration - Description and determination of seated postures with reference to whole-body vibration. Draft TR. 2010.

29. Stokes IA, Gardner-Morse M. Lumbar spine maximum efforts and muscle recruitment patterns predicted by a model with multijoint muscles and joints with stiffness. J Biomech. 1995 Feb;28(2):173-86.

30. Thomae MK, Porteous JE, Brock JR, Allen GD, Heller RF. Back pain in Australian military helicopter pilots: a preliminary study. Aviat Space Environ Med. 1998 May;69(5):468-73.

31. Tissot $F$, Messing K, Stock $S$. Studying the relationship between low back pain and working postures among those who stand and those who sit most of the working day. Ergonomics. 2009;52(11):1402 - 18.

32. Van Dieen JH. Asymmetry of erector spinae muscle activity in twisted postures and consistency of muscle activation patterns across subjects. Spine (Phila $\mathrm{Pa}$ 1976). 1996 Nov 15;21(22):2651-61.

33. Viswamurthy SR, Ganguli R. Effect of Piezoelectric Hysteresis on Helicopter Vibration Control Using Trailing-Edge Flaps. J Guid Contr Dynam. 2006;29(5):120109. 
TABLE I. THE DIFFERENT PROFILES AND THEIR OPERATIONAL SPEED IN KNOTS.

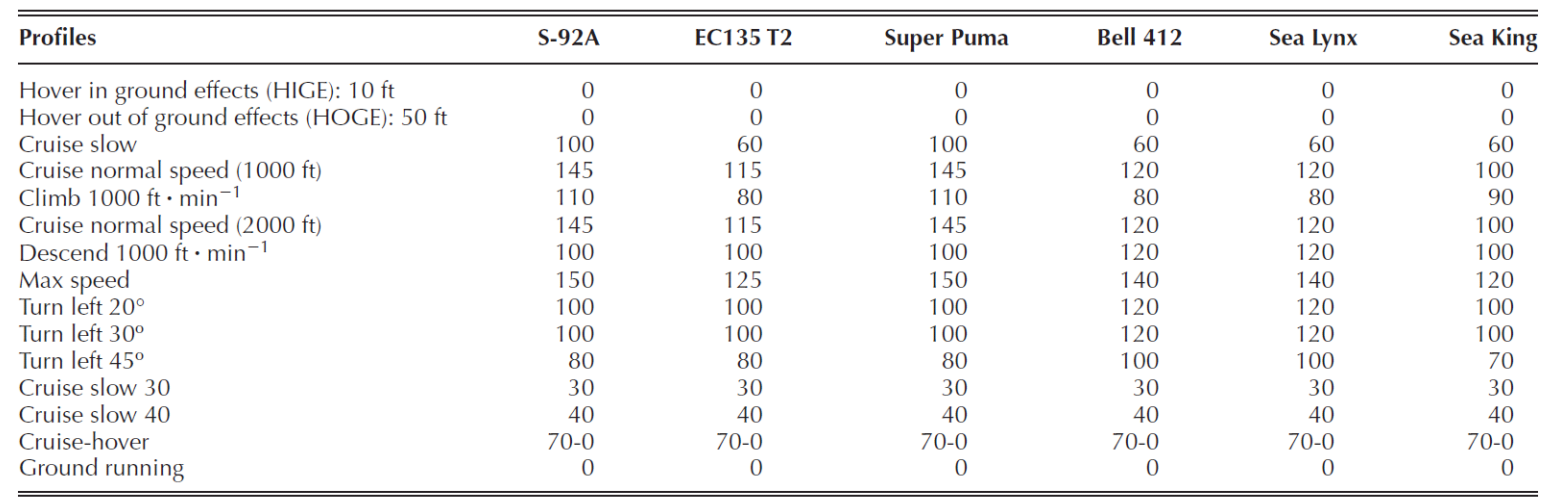

TABLE II. PROFILES WITH THEORETICAL WORKING DAY FOR A MILITARY HELICOPTER PILOT AND FOR A CIVILIAN HELICOPTER PILOT FLYING OFFSHORE.

\begin{tabular}{lcc}
\hline \hline Profile & Military Range (minutes) & $\begin{array}{c}\text { Civilian Range } \\
\text { (minutes) }\end{array}$ \\
\hline HIGE $10 \mathrm{ft}$ & 15 & 5 \\
HOGE $50 \mathrm{ft}$ & 20 & 5 \\
Cruise slow & 40 & 20 \\
Cruise normal $1000 \mathrm{ft}$ & 90 & 20 \\
Climb 1000 ft $\cdot \mathrm{min}^{-1}$ & 35 & 20 \\
Cruise high $2000 \mathrm{ft}$ & 40 & 160 \\
Descend $1000 \mathrm{ft} \cdot \mathrm{min}^{-1}$ & 20 & 25 \\
Max speed & 35 & 160 \\
Turn left $20^{\circ}$ & 35 & 10 \\
Turn left 30 & 10 & 5 \\
Turn left $45^{\circ}$ & 30 & 0 \\
Slow speed 30 & 10 & 0 \\
Slow speed 40 & 30 & 10 \\
Cruise-hover & 40 & 0 \\
Ground running & 30 & 40 \\
TOTAL & 480 & 480 \\
\hline \hline
\end{tabular}

HIGE $=$ Hover in ground effects; HOGE = Hover out of ground effects . 
Worst axis

A(8) (with $x, y$ scaling)

A(8) (no $x, y$ scaling)

Ground running

Cruise-hover

Slow speed (40)

Slow speed (30)

Turn left $45^{\circ}$

Turn left $30^{\circ}$

Turn left $20^{\circ}$

Max speed (Vne)

Descend $1000 \mathrm{ft} \cdot \mathrm{min}^{-1}$

Cruise high $(2000 \mathrm{ft})$

Climb $1000 \mathrm{ft} \cdot \mathrm{min}^{-1}$

Cruise normal (1000 ft)

Cruise slow speed

HOGE $(50 \mathrm{ft})$

HIGE (10 ft)

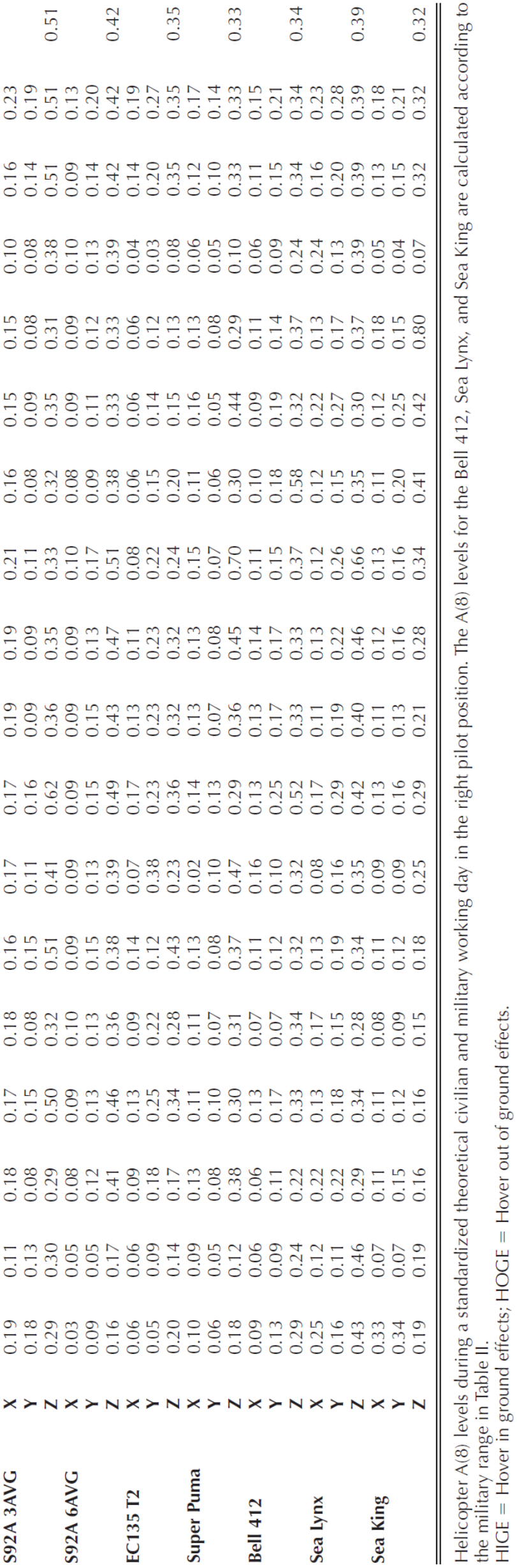

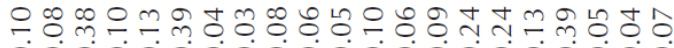

늠ำ

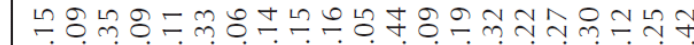

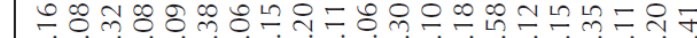

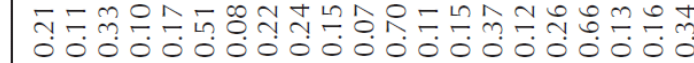

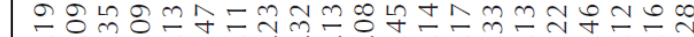

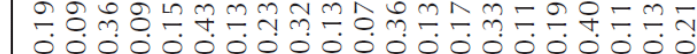

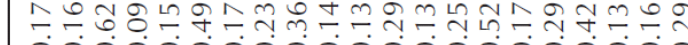

(1)

$\stackrel{\infty}{\infty}$

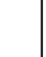




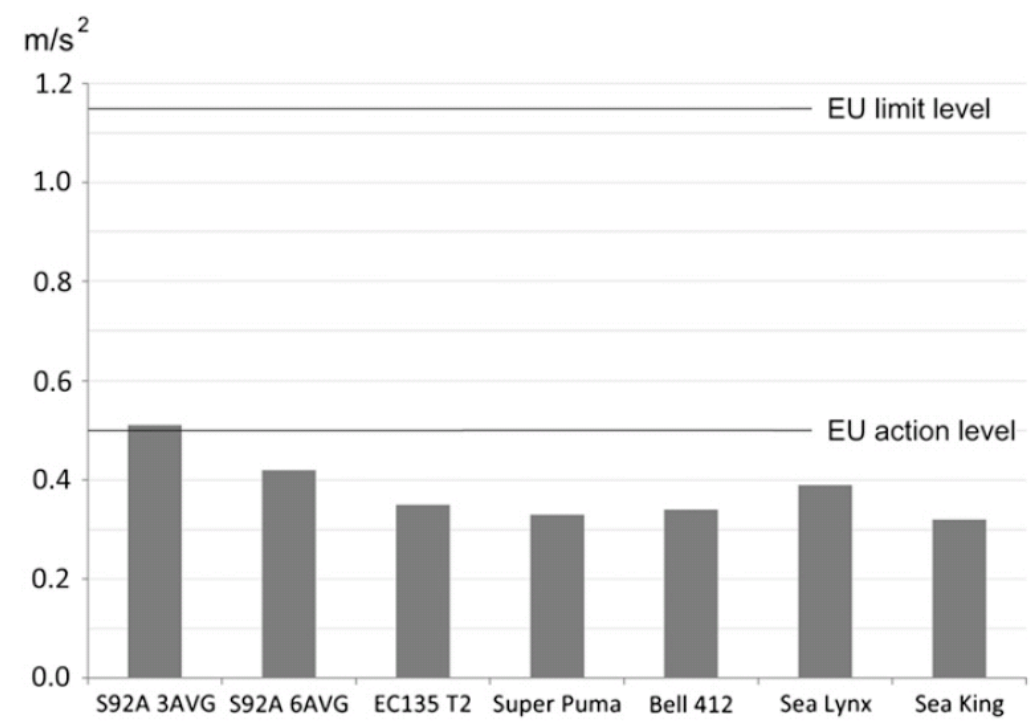

Fig. 1. Calculated $A(8)$ worst axis levels in relation to the EU levels. 